\title{
Reflexos da mídia na formação de hábitos alimentares de crianças e adolescentes a nível global - uma revisão bibliográfica
}

\author{
Media reflections on the formation of eating habits of children and adolescents at a global level - a
} literature review

Reflexiones mediáticas sobre la formación de hábitos alimentarios de niños y adolescentes a nivel mundial - una revisión de la literatura

\section{Resumo}

A mídia possui estratégias que apelam para o público infanto-juvenil de forma exagerada, lucrando cada vez mais com a vendas de seus produtos. O estudo objetivou descrever o poder de influência que meios de comunicação exerce sobre as escolhas alimentares de crianças e adolescentes. Trata-se de um estudo bibliográfico, por meio de revisão de literatura com a realização de buscas eletrônicas. A publicidade impulsiona a população à escolhas alimentares inadequadas gerando problemas à saúde. Com o aumento da prevalência da obesidade infantil, medidas precisam ser tomadas para monitorar a comercialização de alimentos. O mundo virtual vem se tornando influente nos últimos anos, contribuindo também para o comportamento dos transtornos alimentares. Os maus hábitos obtidos na juventude podem influenciar o desempenho alimentar ao longo da vida, refletindo fatores de risco para o desenvolvimento de doenças crônicas não transmissíveis e traumas psicológicos. Uma proibição efetiva da divulgação de produtos alimentícios dirigida à criança é essencial para proteger seus direitos, integridade física, psicológica e moral. Por fim, faz-se necessário refletir sobre a importância do monitoramento de publicidades que promovem alimentos que não são saudáveis. Além disso, é imprescindível que todos se conscientizem a respeito das consequências que a obesidade pode causar a longo prazo na saúde de crianças.

Palavras-chave: Influência da mídia na alimentação infantil; Obesidade infantil; Transtornos alimentares; Obesidade na adolescência; Marketing da indústria de alimentos.

\begin{abstract}
The media has strategies that exaggerately appeal to children and young people, profiting more and more from the sale of their products. The study aimed to describe the power of influence that the media exert on the food choices of children and adolescents. This is a bibliographic study, through a literature review with electronic searches. Advertising drives the population to inappropriate food choices, causing health problems. With the increasing prevalence of childhood obesity, measures need to be taken to monitor food marketing. The virtual world has become influential in recent years, also contributing to the behavior of eating disorders. Bad habits obtained in youth can influence dietary performance throughout life, reflecting risk factors for the development of non-communicable chronic diseases and psychological trauma. An effective ban on the dissemination of food products aimed at children is essential to protect their rights, physical, psychological and moral integrity. Finally, it is necessary to reflect on the importance of monitoring advertisements that promote unhealthy foods. In addition, it is essential that everyone is aware of the consequences that obesity can have on the long-term health of children.
\end{abstract}

Keywords: Media influence on infant feeding; Child obesity; Eating disorders; Adolescent obesity; Food industry marketing. 


\section{Resumen}

Los medios de comunicación tienen estrategias que atraen exageradamente a los niños y jóvenes, beneficiándose cada vez más de la venta de sus productos. El estudio tuvo como objetivo describir el poder de influencia que los medios de comunicación ejercen sobre las elecciones alimentarias de niños y adolescentes. Se trata de un estudio bibliográfico, a través de una revisión de la literatura con búsquedas electrónicas. La publicidad lleva a la población a elegir alimentos inadecuados, lo que genera problemas de salud. Con la creciente prevalencia de la obesidad infantil, se deben tomar medidas para monitorear la comercialización de alimentos. El mundo virtual se ha vuelto influyente en los últimos años, contribuyendo también al comportamiento de los trastornos alimentarios. Los malos hábitos adquiridos en la juventud pueden influir en el rendimiento dietético a lo largo de la vida, reflejando factores de riesgo para el desarrollo de enfermedades crónicas no transmisibles y traumas psicológicos. Una prohibición efectiva de la difusión de productos alimenticios destinados a los niños es fundamental para proteger sus derechos, integridad física, psicológica y moral. Finalmente, es necesario reflexionar sobre la importancia de monitorear los anuncios que promueven alimentos poco saludables. Además, es fundamental que todo el mundo sea consciente de las consecuencias que puede tener la obesidad en la salud a largo plazo de los niños.

Palabras clave: Influencia de los medios en la alimentación infantil; Obesidad infantil; Trastornos de la alimentación; Obesidad adolescente; Marketing de la industria alimentaria.

\section{Introdução}

Henriques, Sally, Burlandy e Beiler, (2012) aborda que nas últimas décadas as práticas alimentares da população brasileira sofreram alterações em virtude das transformações ocorridas no dia a dia de vida e trabalho das pessoas, devido à diversos fatores que marcam a vida contemporânea, como, o desenvolvimento das cidades, urbanização, industrialização, marketing e as várias atribuições da mulher, que na maioria das famílias, é quem exerce papel principal no cuidado com à saúde e a alimentação de todos além de trabalhar fora de casa. Esses e diversos outros fatores como, a realização de refeições fora de casa que é visto como praticidade e otimização do tempo, contribuem na construção de um comportamento alimentar inadequado e principalmente, para o elevado consumo de alimentos industrializados.

“Ainda que a TV seja um importante meio para a difusão de informação, ela é capaz de exercer uma influência negativa sobre as escolhas alimentares de jovens" (Enes \& Lucchini, 2016). Com o enorme alcance das mídias em todas as faixas etárias e classes sociais os meios de comunicação tem um poder de influência altíssimo sobre o consumo dos alimentos, principalmente para as crianças, pois na alimentação está envolvida não só a necessidade, mas o desejo. Dessa forma a mídia possui estratégias que apelam para o público infanto-juvenil de forma exagerada, visando lucros exponenciais.

"Considera-se os adolescentes como um grupo etário em transição, vivendo sob a plena revolução tecnológica e os efeitos da mídia, constata-se o quanto esse grupo está sujeito às vulnerabilidades próprias dessa condição" (Bittar \& Soares, 2020). Nessa fase há uma grande transformação, e entre elas a mudança no hábito alimentar, que pode ser alterado ocasionando um excesso ou baixo peso e geralmente é influenciado pelo o que é exposto nos meios de comunicação.

Segundo Para Martins (2018) estima-se que 50\% dos alimentos divulgados são voltados ao público infantil, sendo usado por indústrias táticas de marketing apelativas e de forma insistente para atrair esse público, sendo que $80 \%$ desses produtos alimentícios divulgados, não são saudáveis, além de conter um teor elevado de sódio, açucares e gorduras, eles não oferecem valor nutricional.

É importante ressaltar a importância da iniciativa da família para que a criança desenvolva e desperte o interesse por uma alimentação equilibrada composta por alimentos que ofereçam nutrientes para a manutenção de sua vida até a fase adulta. Para Rocha et al. (2018), é importante alertar as crianças quanto ao elevado consumo de alimentos processados e ultraprocessados, papel exercido tanto pelos cuidadores, quanto aos profissionais da área da saúde. Além de ressaltar a importância de uma educação alimentar e nutricional nas escolas, como forma de reforçar a alimentação saudável da família. 


\section{Metodologia}

Trata-se de um estudo bibliográfico, por meio de revisão sistemática que consistiu na busca e análise de artigos e livros relacionados a uma determinada área da ciência aprimorando descobertas e ideias, como traz Pereira et al. (2018. Para tal, foram realizadas buscas eletrônicas na base de dados, SciELO, Portal de Periódicos CAPES/MEC, PubMed, Medline, Lilacs e, Science Direct.

As palavras-chaves utilizadas para buscas do material bibliográfico foram influência da mídia na alimentação infantil, alimentação infantil e tecnologia, obesidade infantil, alimentação saudável, educação nutricional, obesidade na adolescência, políticas contra consumo de alimentos ultraprocessados, transtornos alimentares, e o marketing da indústria de alimentos.

Em relação aos artigos, foram analisadas informações contidas nas bases de dados citadas anteriormente, buscando uma visão clara dos resultados e capacidades que os meios de comunicação exercem em relação a alimentação infantil. Mediante a um processo de seleção, foram descartados estudos que por sua vez não apresentavam informações relacionadas ao tema abordado. Portanto, foram excluídos da pesquisa termos relacionados a obesidade em idosos, transtornos alimentares em adultos e influência da mídia nos hábitos alimentares na fase adulta.

\section{Resultados e Discussão}

\section{A importância da alimentação saudável}

Para Paiva, Magalhães, Santos, Santos e Trad (2019) as recomendações para uma refeição apropriada e saudável baseiam-se no equilíbrio, reduzindo o consumo de produtos alimentícios hoje conhecidos como ultraprocessados e incentivando o consumo dos naturais. No ponto de vista de Santos, Silva e Pinto (2018) o ato de incluir hábitos saudáveis na rotina de uma criança pode ser desafiador, porque é nesta fase que eles desenvolvem e reconhecem os alimentos. Entretanto, alimentação é um fator de grande importância, e nos primeiros anos de vida se torna essencial uma ingesta alimentar correta para que a criança cresça de forma saudável.

Segundo Willig, Lenardt e Caldas (2015), o alcance da longevidade também é baseada na inclusão de hábitos saudáveis ainda na infância, optando por uma refeição nutritiva. Sendo assim, é fundamental obter boas escolhas alimentares podendo ser compreendida a partir da introdução alimentar nos primeiros seis meses de vida, que garantem o crescimento e desenvolvimento saudável.

De acordo com Alves e Cunha (2020) a alimentação é um direito de todos, sendo assim o ato de comer deve ser compreendido como uma garantia de uma melhor qualidade vida, preferindo o consumo de alimentos saudáveis e evitando os industrializados e ultraprocessados, zelando pela saúde presente e futura.

Para Dutra e Malagoli (2019) deve-se considerar a importância que determinados alimentos possuem para a saúde de um indivíduo, e o quanto se faz necessário o cultivo de alimentos naturais, dando valor tanto ao consumo, quanto às propriedades nutricionais.

“O Brasil tem um longo histórico de políticas públicas voltadas à superação de carências nutricionais e, mais recentemente, à superação da epidemia de sobrepeso/obesidade” (Paiva, Magalhães, Santos, Santos \& Trad, 2019). Portanto, do ponto de vista de Furtado e Szapiro (2016), além de políticas sociais que devem disponibilizar espaços recreativos para lazer, ambientes propícios para prática de atividades físicas e informações básicas sobre saúde, a mudança de hábitos alimentares dependem da sociedade e suas escolhas individuais.

\section{Importância da educação nutricional em escolas}

Crianças e adolescentes passam boa parte do tempo em escolas ou creches, trocam ideias, brincadeiras e até mesmo lanches, porém cada um possui gostos e escolhas alimentares diferentes. Diante disso, podemos mencionar a importância da 
educação nutricional em escolares, como atividades criativas que atraem a sua atenção. Para Coelho e Bógus (2016), da agricultura à cozinha, as crianças podem sentir o verdadeiro valor de uma alimentação saudável quando estão em contato direto com os alimentos, portanto para o autor, uma escola que tenha horta ajuda a atrair a curiosidade dos alunos sobre a produção de alimentos e estabelecendo uma relação diferente quanto ao consumo de determinados alimentos.

Pedraza (2017), realizou um estudo em uma escola de Capina Grande, Paraíba, com intuito de analisar o estado nutricional dos escolares, o valor amostral foi de 1081 escolares de 5 à 10 anos. A idade escolar da população estudada foi de $245(22,7 \%)$ alunos primeiro ano, segundo ano 258 (23,9\%), terceiro ano 242 (22,3\%), quarto ano 204 (18,9\%), quinto ano 132 $(12,2 \%)$ (Gráfico 1).

Gráfico 1 - Distribuição da população do estudo de acordo com o ano escolar.

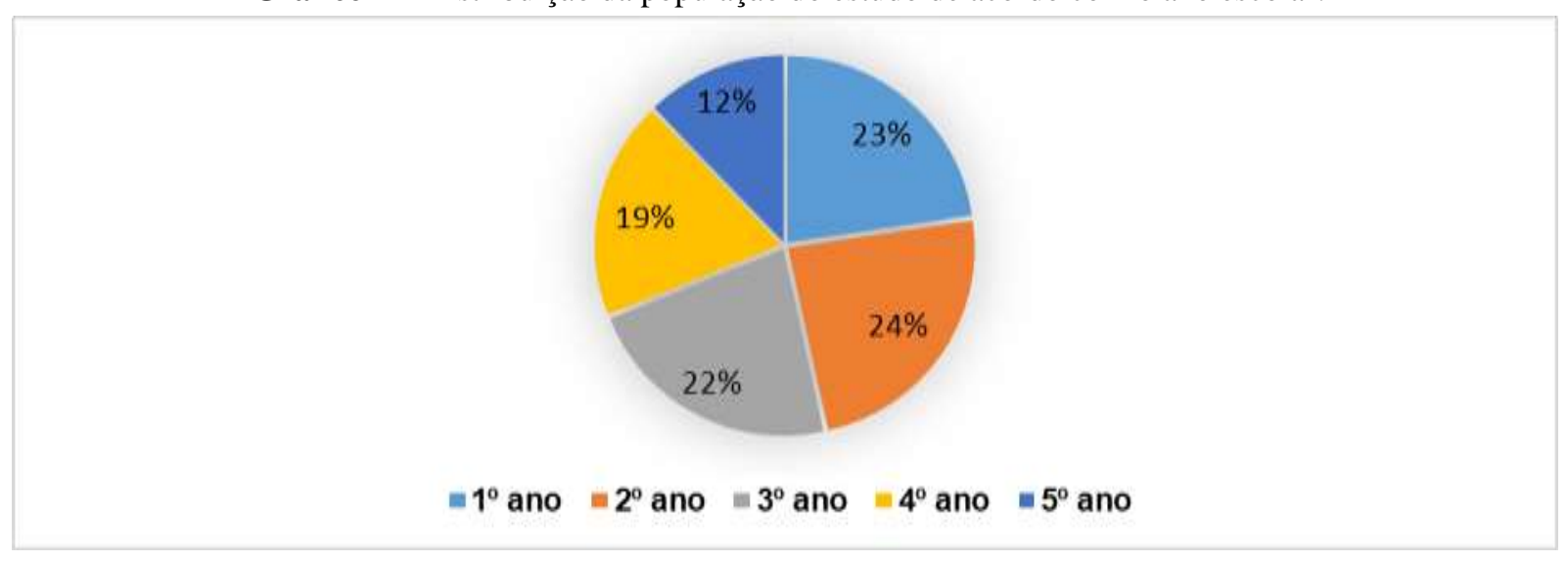

Fonte: Adaptado de Pedraza (2017).

De acordo com os dados do ano escolar, foi possível observar que a população maior do estudo foi de alunos do segundo ano. Relacionado ao diagnóstico do estado nutricional obteve os seguintes resultados, (26) 2,4\% dos escolares apresentavam déficit em sua estatura, 21,5\% (232) estavam com excesso de peso, (133) 12,3\% com sobrepeso e (99) 9,2\% obesos. Foi possível observar que um número maior de escolares aparentava excesso de peso (Gráfico 2).

Gráfico 2 - Diagnóstico do estado nutricional de escolares de 5 a 10 anos de idade.

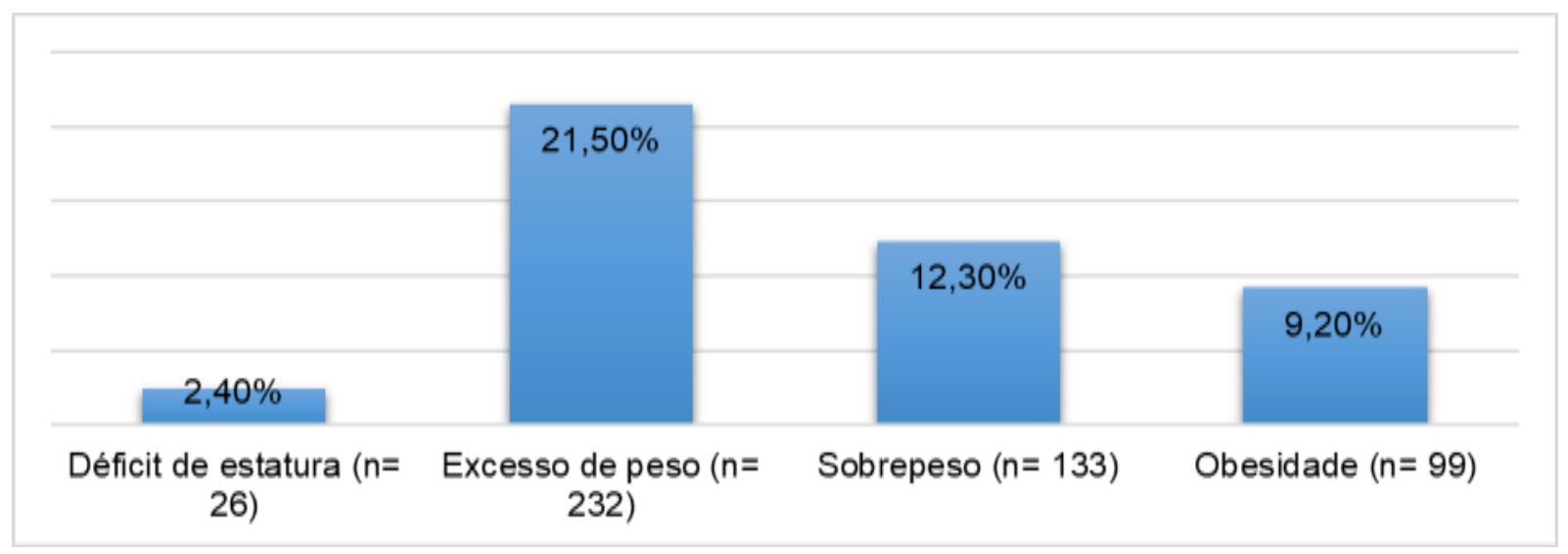

Fonte: Adaptado de Pedraza (2017).

Constatou-se, que em relação aos hábitos alimentares, o resultado observado foi que (701) 64,85\% dos alunos tinham o hábito de tomar café pela manhã com frequência ou na maioria dos dias; (529) 48,94\% tinham prática de realizar todas as 
refeições; (132) 12,21\% não consumiam frutas e/ou verduras; (508) 46,99\% Comia na hora do lanche sorvete, doces, biscoitos doces / sanduíches e refrigerantes, e (240) 22,20\% lanchavam salgadinhos, batatas fritas ou alimentos semelhantes aos citados (Gráfico 3). "Estado nutricional dos escolares apresenta-se com características da transição nutricional, marcada pelo aumento no indicador de sobrepeso/obesidade" (Pedraza, 2017).

Gráfico 3 - Hábitos alimentares de crianças escolares de 5 a 10 de idade.

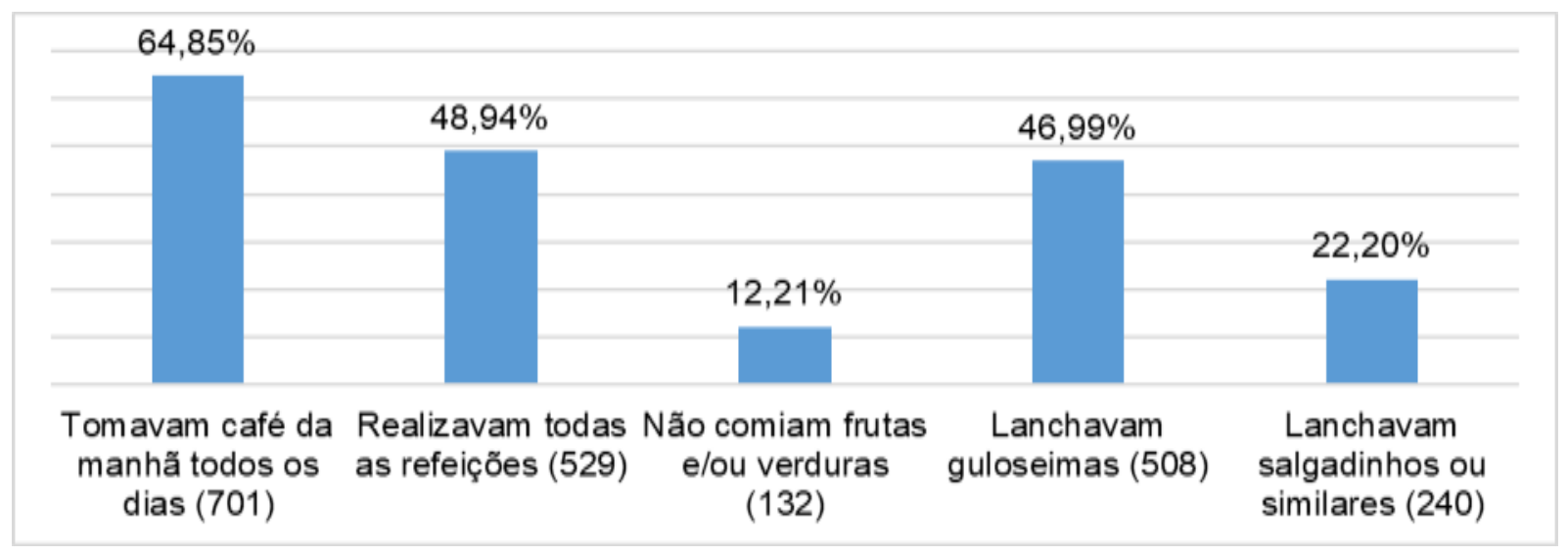

Fonte: Adaptado de Pedraza (2017).

Foi realizado um estudo por Santos e Bergold (2018) na cidade de Macaé (Rio de Janeiro) em uma escola pública com estudantes do ensino fundamental. Participaram das atividades crianças e adolescentes com idade entre 5 e 15 anos, um total de dez turmas do $1^{\circ}$ ao $5^{\circ}$ ano do ensino fundamental, a amostra total foi de 1107 escolares. Com o objetivo de promover saúde meios estratégicos foram utilizados nas atividades educativas, como músicas e atividades lúdicas que foram realizadas junto aos escolares. Escolares relataram que após atividade educativa realizada na escola relacionada aos alimentos ultraprocessados, conseguiram incentivar seus familiares quanto a importância da leitura de rótulos dos alimentos.

Para Prado, Sousa Junior e Pires (2017), professores e profissionais da área da saúde devem usar a imaginação com estratégias de ensino que chame a atenção do público infantil, um exemplo é a utilização de personagens animados para promover saúde, como as histórias em quadrinhos, e é considerado um importante item de entretenimento para esse público.

No ponto de vista de Greenwood e Fonseca (2016), o desenvolvimento da Educação Alimentar Nutricional (EAN) no âmbito escolar é de grande importância, uma vez que os alunos ali inseridos estão, não apenas durante o desenvolvimento físico, mas, também, para moldar seus conceitos e valores em relação à alimentação.

Dias, et al. (2016), cita que a aplicação de atividades lúdicas e o uso de jogos na educação em saúde são populares entre o público infantil e podem torná-los mais interessado. Na visão de Cassemiro et al. (2015), a partir do desenvolvimento de uma Educação Alimentar Nutricional (EAN) crítica, participativa, contínua e diária baseia-se em uma alimentação atrelada ao Direito Humano à Alimentação Adequada (DHAA). A escola torna-se um terreno fértil para este enorme esforço de garantir uma nutrição adequada e saudável de forma sustentável e justa para todos.

\section{Influência do marketing nutricional}

Uma pesquisa realizada em 27 cidades do Brasil em 2016 pela Vigitel mostra dados de frequência de adultos que despendem três horas ou mais por dia do seu tempo livre assistindo à televisão ou usando computador, tablet ou celular foi de 61,7\%, sendo semelhante em homens e mulheres (Brasil, 2016). Este estudo mostra como as pessoas são expostas a mídias 
influentes, com a promoção de alimentos não nutritivos, sendo que a importância de ensinar as crianças sobre boas escolhas alimentares e o uso das redes sociais, informações estas que devem partir de um adulto.

Do ponto de vista de Santos e Batalha (2010), a publicidade de alimentos é apontada como uma das causas que leva à escolhas alimentares inadequadas da população e gera problemas à saúde como hipertensão, diabetes e principalmente obesidade infantil, devido ao elevado alto teor de sódio, açucares e, gorduras.

Royo-Bordonada, Bosqued-Estefanía, Damián, López-Jurado e Moya-Geromini (2016), realizou um estudo em 2012 na Espanha, a fim de analisar publicidades de alimentos com alta densidade energética e sem valor nutricional voltados ao público infantil. Foi constatado que a maior parte de todos os alimentos vendidos na televisão espanhola para esse público contém alguma forma de argumentação nutricional ou de saúde como sendo um alimento fortificado, portanto a maioria das alegações eram direcionadas à produtos lácteos, induzindo ao erro nos hábitos alimentares da população infantil espanhola.

Penteado, Costa e Rodrigues (2018) cita a utilização da ótica da animação e personagens. Existem produtos e serviços voltados para crianças e adolescentes, incluindo bonecos, jogos, brinquedos, livros, cadernos, mochilas, caixas, lápis, borrachas e outros materiais escolares, roupas, calçados, acessórios, festas de decoração, comida, etc., além da utilização da criação de ambientes afetuosos, fazendo com que o público infanto-juvenil seja conduzido ao erro em suas escolhas alimentares e nutricionais ao ser seduzido por um mundo fantasioso.

Bittar e Soares (2020) ressaltam que a mídia vem se tornando um meio de comunicação influente nos últimos anos, e contribui para o comportamento dos transtornos alimentares. Dessa perspectiva, podemos visualizar o poderoso impacto da mídia no comportamento alimentar dos indivíduos, especialmente crianças e adolescentes.

Segundo Gravatá, Alves e Fernandes (2019), é importante que profissionais da saúde que lidam com crianças saibam que a influência da mídia é uma preocupação social. Dependendo da proporção, existe a possibilidade de intervenção direta e/ ou indireta, durante o desenvolvimento infantil.

"Nesse cenário, a publicidade, uma das molas propulsoras da sociedade de consumo, propõe-se a influenciar as escolhas dos indivíduos" (Santos, Oliveira, Peres, Leonidas e Oliveira-Cardoso, 2019). Com base no que afirma o autor, podese dizer que é importante que a população não se deixe influenciar pelo que é exposto. Para tal, o senso crítico, em relação às afirmações que chegam ao infante, deve ser constantemente estimulado. Pois existem diversas informações e propagandas que incitam o consumidor ao erro.

Na visão de Contreras e Gracia (2015), a aplicação de novas tecnologias e seus avanços na inovação alimentar tem sido bastante acelerada. Além disso o aumento da saturação do mercado alimentar e a intensificação da concorrência global, obrigam as empresas a inovar continuamente na criação de novos produtos e aumentar ainda mais o seu valor de mercado.

\section{Obesidade infantil uma consequência das escolhas alimentares}

Penha et al. (2018) cita que por muitos anos era entendido que as complicações vindas da obesidade ocorriam exclusivamente no público adulto, mesmo compreendendo seu efeito no público infantil. Existem estudos que comprovam as consequências negativas do ganho de peso no público infantil e seu consequente prejuízo na saúde, e a responsabilidade por isso é uma alimentação inadequada, principalmente ligada à falta de atividade física, e a um número crescente de doenças crônicas, além da exclusão que essas crianças sofrem em consequência do bullying. "Em 2016, estima-se que 42 milhões de crianças menores de 5 anos estavam acima do peso ou obesas; quase três quartos deles vivem na Ásia e África" (OMS, 2018).

Para Machado, Ferreira e Rangel (2019), a criança é o reflexo dos pais, portanto, se eles não dispuserem de uma prática de vida saudável a criança vai seguir o exemplo, dessa forma é importante a realização de atividades físicas cotidianamente e mudança de hábitos alimentares. Do ponto de vista de Warkentin, Mais, Latorre, Carnell e Taddei (2018), 
instruir os pais sobre o peso de seus filhos deve ser um primeiro passo importante na promoção de um ambiente e estilo de vida saudável, bem como na prevenção e tratamento da obesidade infantil.

Bankoff, Bispo e Sousa (2020) cita que com o envelhecimento, fator incorrigível, as doenças crônicas não transmissíveis ocorrem muito cedo no indivíduo, o que já está acontecendo em nossa sociedade devido à obesidade, diabetes e hipertensão em crianças e adolescentes. Para Giuglian (2018), é importante enfatizar a importância de monitorar o desenvolvimento e os hábitos alimentares da criança desde os primeiros anos de vida, esses cuidados estabelecem uma prevenção de saúde na sua vida presente e futura. Portanto, é necessário manter hábitos saudáveis desde a infância, alimentarse corretamente, praticar atividades físicas e enfatizar a importância na redução da exposição à mídia, como televisão, internet, telefones celulares e computadores, evitando a possibilidade de influenciar negativamente nas escolhas alimentares. No entanto, o convívio familiar está menos frequento devido a ocupação dos pais ou cuidadores, sendo assim crianças e adolescentes ficam mais expostos aos meios virtuais quando não acompanhados ou monitoradas.

Ferreira, Szwarcwald e Damacena (2019) mencionam que a taxa de obesidade da população brasileira deve ser monitorada para compreensão dos padrões e fatores de risco, garantindo uma prevenção à obesidade infantil e promovendo hábitos saudáveis na sociedade brasileira, sendo fundamental o apoio a políticas públicas.

\section{Adolescentes e seus hábitos alimentares}

De acordo com Sousa et al. (2019), a adolescência é um período da vida caracterizado por estímulos de persuasão à hábitos e comportamentos, deixando esse público vulnerável no ato de suas escolhas. Os maus hábitos obtidos nesta fase podem influenciar o comportamento alimentar ao longo da vida, refletindo fatores de risco para o desenvolvimento de doenças crônicas não transmissíveis e traumas psicológicos. Para Ross et al. (2020), a juventude é uma parte importante da vida, e o bem-estar do adolescente em si se torna um bem não só pessoal, mas também coletivo.

"Um dos fatores que pode influenciar as escolhas alimentares dos adolescentes está relacionado com os hábitos familiares relacionados com a alimentação" (Cardoso, Santos, Nunes \& Loureiro, 2015). Além disso, podemos citar a influência das publicidades de alimentos associados ao marketing. Um estudo realizado por Enes e Lucchini (2016), mostra que hábitos praticados por adolescentes, como assistir televisão, podem estar associados à um estilo de vida que não é considerado saudável, diminuindo o consumo de frutas, legumes e verduras, e substituindo por alimentos divulgados através de campanhas publicitárias que não beneficiam a saúde.

Mediante um estudo realizado com 59 adolescentes entre, treze e dezesseis anos, por Pereira, Pereira \& AngelisPereira (2017) em uma escola municipal, no município de Larvas, estado de Minas Gerais, observou que, em relatos, todos os escolares tinham o hábito de consumir doces, entretanto 40,68\% deles declararam o consumo de doces de três ou mais vezes ao dia. 16,95\% consumiam com a mesma frequência lanches tipo fast food, fazendo parte dos hábitos dos demais alunos, porém não com a mesma repetição. Relacionado a frequência de consumo de refrigerantes, 35,59\% assumiram a ingesta de duas vezes ao dia. Enquanto ao consumo de frutas, verduras, e legumes, somente $27,73 \%$ relataram o consumo de três ou mais frutas ao dia, e 13,56\% consumiam verduras e legumes com a mesma equivalência (Gráfico 4). 
Gráfico 4 - Hábitos alimentares de estudantes adolescentes de 13 à 16 anos participantes da pesquisa.

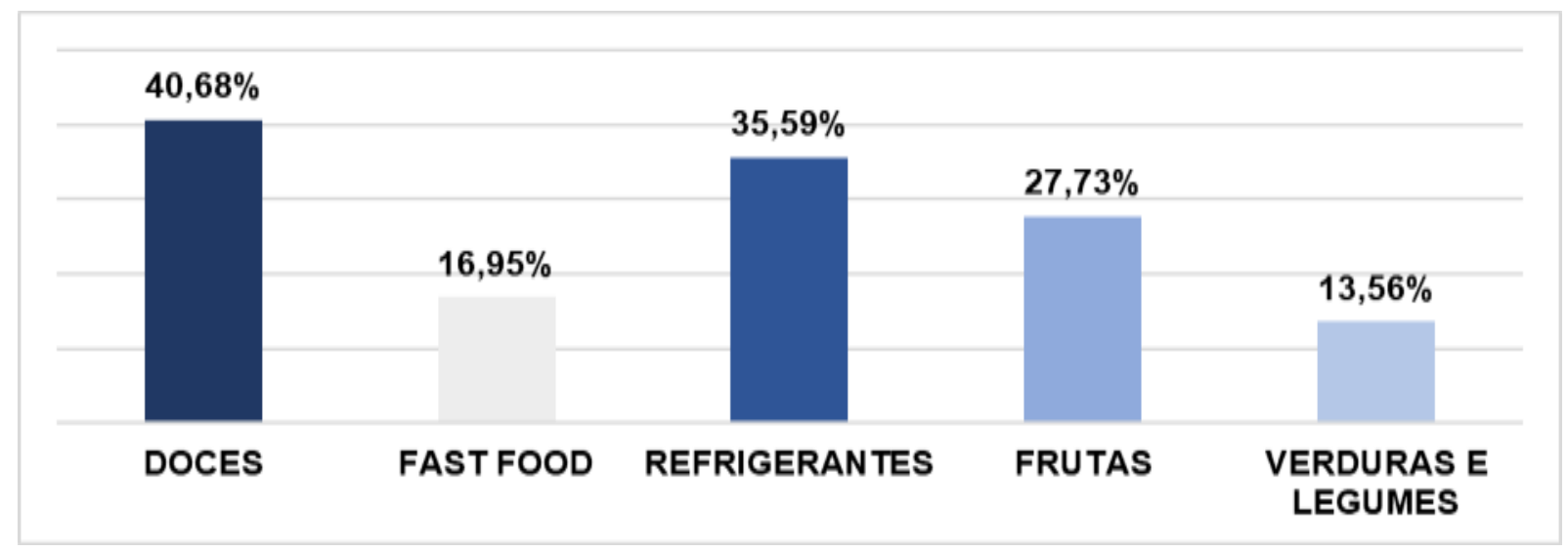

Fonte: Adaptado de Pereira, Pereira e Angelis-Pereira (2017).

Segundo Silva e Ferreira (2019, p. 8),

"O adolescente tem conhecimentos elaborados no senso comum, decorrentes de suas experiências e da comunicação do grupo, e isso gera uma rede de informações a partir do saber popular, e o consumo cotidiano de alimentos gordurosos é relevante e preocupante".

Em vista disto, eles estabeleceram uma unidade de conhecimento e ação, porém priorizando preferência e prazer de comer de forma específica.

\section{Transtornos alimentares na adolescência e sua relação com a mídia}

Mahan e Raymond (2018) cita que os transtornos alimentares são identificados por distúrbios persistentes na alimentação ou em hábitos referentes à alimentação, causando graves prejuízos à saúde física e às funções psicossociais.

De acordo com Bittar e Soares (2020), os tempos em que vivemos são diferentes de todos os anteriores, sendo nomeado por intelectuais como o pós-modernismo, caracterizado pela globalização e revolução tecnológica reduzindo as fronteiras entre nações, povos e costumes.

Na visão de Freitas e Cardoso (2020), com o aumento da tecnologia associado ao alcance da mídia, empresas de estéticas estão cada vez mais trabalhando na otimização do corpo, com a remoção de manchas, marcas e outros. Para Bittar e Soares (2020), a prevalência dos transtornos alimentares, o crescimento da mídia e a predominância de informações sobre saúde, dieta e alimentação, são causas que requer mais estudos. Por outro lado, muitos jovens são influenciados pela indústria do capitalismo cultural e querem ter o corpo intitulado "corpo perfeito" definido pela própria indústria e idealizado pela sociedade um padrão estético, fator este que pode causar sofrimento e decepção.

Oliveira e Machado (2021) observou em um estudo que os discursos voltados sobre a tecnologia vêm fazendo parte na vida de adolescentes, sendo acessado com maior frequência as redes sociais, e a construção de sua identidade pode ser afetada devido à forte influência que a mídia exerce sob esses adolescentes, principalmente por estarem muito tempo expostos a esse mundo virtual.

O público com maior risco de desenvolvimento de transtornos alimentares na visão de Fortes, Filgueira, Oliveira, Almeida e Ferreira (2016), são adolescentes, que estão com autoestima baixa, apresentando humor negativo, depressivo e maior perfeccionismo.

Estudo realizado por Zicgraf e Elkins (2018) cita que crianças e adolescentes ansiosas costumam ser mais vulneráveis a impulsos sensoriais, e essa sensibilidade aumentada incluindo o comportamento alimentar exigente e neofobia alimentar. 
Lira, Ganen, Lore e Alvarenga (2017) realizou um estudo no estado de São Paulo onde participou 212 meninas entre 15 e 19 anos de idade, eutróficas, pertencentes às classes sociais D e E, comprovou que $80 \%$ dessas jovens estavam insatisfeitas com seu corpo, insatisfação maior presente em meninas com obesidade e sobrepeso (Tabela 1).

Tabela 1 - Análise da satisfação corporal com relação ao estado nutricional de crianças e adolescentes do sexo feminino.

\begin{tabular}{ccc}
\hline Variáveis & Satisfeita & Insatisfeita \\
\hline Idade (anos) & $30(14,2)$ & $182(85,8)$ \\
$\mathbf{1 0 - 1 4}$ & & \\
$\mathbf{1 5 - 1 9}$ & $10(12,2)$ & $72(87,8)$ \\
Estado nutricional & $20(15,4)$ & $110(84,6)$ \\
Magreza & & $\ldots$ \\
Eutrofia & $\ldots$ & $111(80,4)$ \\
Sobrepeso & $27(19,6)$ & $51(96,2)$ \\
Obesidade & $2(3,8)$ & $15(93,8)$ \\
Obesidade grave & $1(6,2)$ & $5(100)$ \\
\hline
\end{tabular}

Fonte: Adaptado de Lira, Ganen, Lore e Alvarenga (2017).

"A anorexia nervosa é um transtorno alimentar caracterizado por preocupações generalizadas e patológicas com o peso e a forma, que levam à ingestão oral restrita e, consequentemente, baixo peso" (Neale \& Hudson, 2020). Para Schebendach e Roth (2018) As características essenciais da anorexia nervosa (AN) envolvem a restrição persistente à ingestão energética; incluindo o medo intenso de engordar ou se tornar obeso, além de hábitos que persistem interferindo na manutenção da massa corporal adequada; e uma perturbação na percepção do própria peso ou forma corporal. "A perda de peso é posteriormente aprendida a ser associada ao objetivo original de comer mais saudável, ser mais apto ou mais fino, e o ganho de peso, então, pode ser percebido como uma ameaça a esse objetivo." (Frank, Guzman \& Shott, 2019).

Marini (2016) Menciona que com o crescimento desses transtornos nos últimos anos e a evidente ênfase na anorexia e na bulimia, houve uma crescente de centros especializados em tratamento de transtornos, a explicação para esse acontecimento está relacionada à centralidade do corpo na composição da identidade e da subjetividade dos dias atuais. Neale e Hudson (2020) cita que há uma complicação possivelmente fatal relacionada à anorexia nervosa, conhecida como síndrome de realimentação, a identificação desta síndrome ocorre durante a avaliação do indivíduo, ingestão alimentar atual, perdas de peso recentes e vômitos, com esse diagnóstico faz-se necessário o acompanhamento de uma equipe de saúde multidisciplinar.

A bulimia nervosa (BN) é um transtorno alimentar que ocorre segundo Mahan e Raymond (2018) inicialmente no período da adolescência ou início da fase adulta. Os sinais da bulimia nervosa (BN) não são fáceis de identificar, devido o índice de massa corpórea normalmente manter-se eutrófico, além disto o paciente que tem esse tipo transtorno mantém segredo, dificultando ainda mais o diagnóstico.

Um estudo transversal realizado por Brandt et al. (2019) em Campina Grande, Paraíba, analisou 858 estudantes do sexo feminino do ensino médio de 14 escolas, incluindo públicas e particulares. As participantes tinham idade de 15 anos $34,1 \%, 16$ anos 33,1\%, 17 anos 23,2\%, 18 anos 8,6\%, o número maior de participantes foram estudantes de escolas públicas, totalizando $76,2 \%$. Foi identificado através do estudo que $42,0 \%$ das adolescentes participantes apresentavam um hábito alimentar que não era normal, utilizando-se de meios errôneos para controlar o seu peso, apresentando assim um risco de comportamento para bulimia (Tabela 2). 
Tabela 2 - Hábitos de risco praticados por adolescentes para controle de peso.

\begin{tabular}{ccc}
\hline Perguntas & Escola pública & Escola particular \\
\hline Uso de pílulas & & \\
Não & $602(76,4)$ & $186(23,6)$ \\
Sim & $46(74,2)$ & $16(25,8)$ \\
\hline Uso de diuréticos & & $191(23,3)$ \\
Não & $627(76,7)$ & $11(34,4)$ \\
Sim & $21(65,6)$ & $180(22,8)$ \\
Uso de laxantes & & $22(36,1)$ \\
Não & $609(77,2)$ & $181(24,9)$ \\
Sim & $39(63,9)$ & $21(17,1)$ \\
Vômito autoinduzido & & $148(24,8)$ \\
Não & $546(75,1)$ & $54(21,3)$ \\
Sim & $102(82,9)$ & \\
Jejum & & \\
Não & $448(75,2)$ & $(78,7)$ \\
Sim & $200(2019)$ & \\
\hline
\end{tabular}

Fonte: Adaptado de Brandt et al. (2019).

É notável que o uso de pílulas em adolescentes de escolas públicas estava mais presente comparado ao de escolas particulares, sendo classes sociais diferentes. A possibilidade alta de desenvolver bulimia nervosa (BN) foi apresentada em $4,8 \%$ das adolescentes. Dentre elas, $1,4 \%$ atingiram o maior ponto de corte para escala de sintomas e gravidade, indicando a alta probabilidade de bulimia nervosa $(\mathrm{BN})$ e risco de alta gravidade. Quanto ao comportamento de compulsão alimentar periódica, $34,5 \%$ comem até se sentirem mal fisicamente, as que se sentem culpadas por exagerarem ao se alimentar apresentou 36,6\% delas. 48,5\% das adolescentes, quase metade delas diziam sentir um desejo incontrolável de comer, ou, $45,2 \%$ em um período curto de tempo exageravam na hora de se se alimentar e, 10,4\% admitiram que comia compulsivamente (Gráfico 5).

Gráfico 5 - Comportamento indicador para desenvolvimento de compulsão alimentar e de bulimia nervosa.

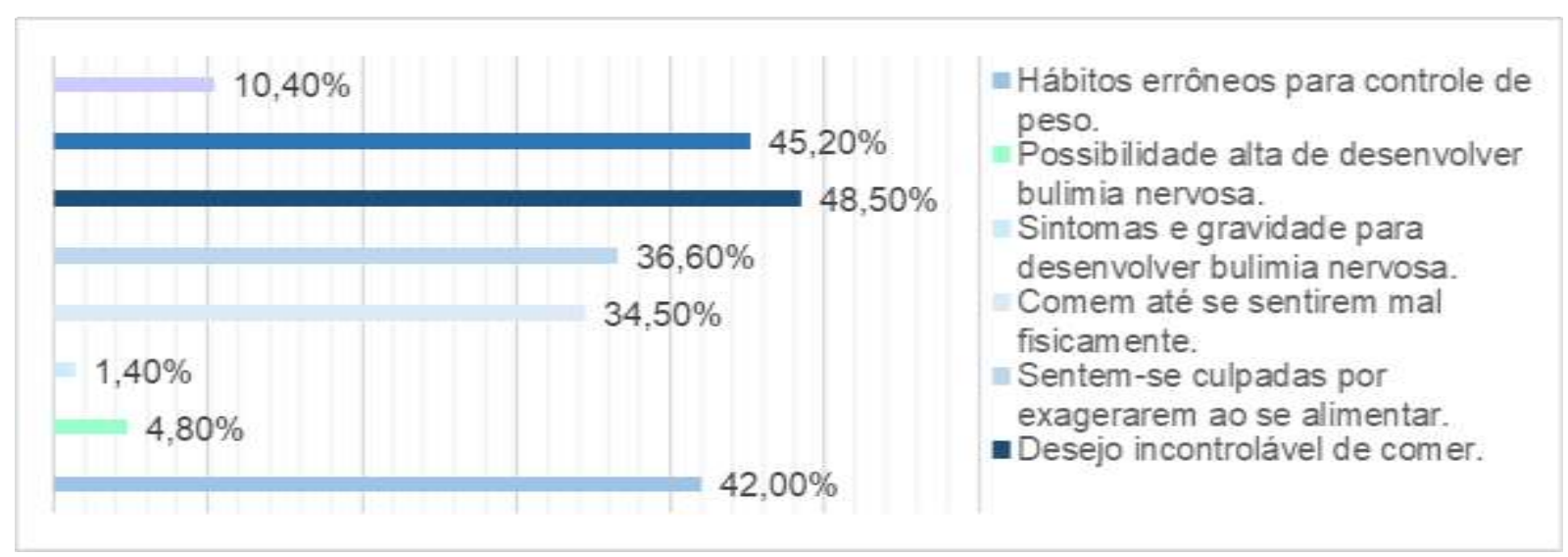

Fonte: Adaptado de Brandt et al. (2019).

A insatisfação corporal entre adolescentes é notada em diversos estudos realizados, Zanolli et al. (2019) através de um estudo, avaliou a insatisfação corporal de adolescentes com idade entre 8 a 12 anos de uma escola pública da Juiz de Fora, Minas Gerais. Dados coletados de 141 estudantes do ensino fundamental observou-se que, 86,5\% um total de 122 alunos estavam insatisfeitos com seu corpo, 19 deles apenas 13,5\% estavam satisfeitos com seu corpo (Gráfico 6). 
Gráfico 6 - Insatisfação corporal de estudantes entre 8 a 12 anos.

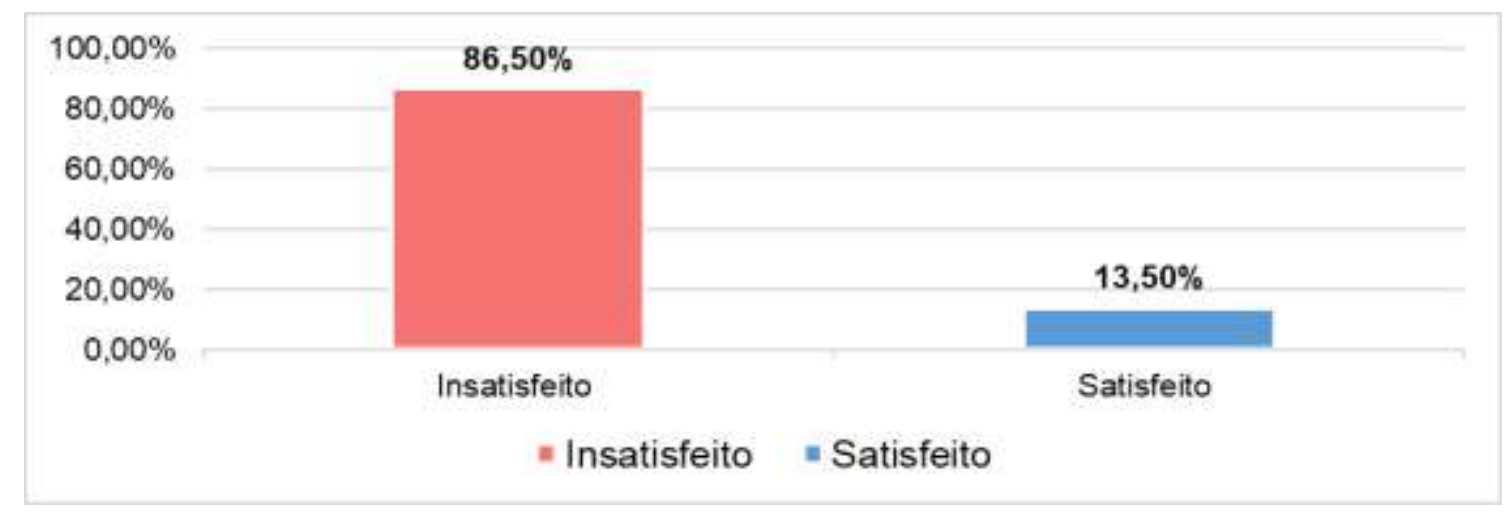

Fonte: Adaptado de Zanolli et al. (2019).

Um estudo piloto realizado em três escolas públicas de ensino médio na cidade de Natal-RN Chimbinha, Jácome, Silva, Barreto \& Costa (2019) apresentou dados que dentre 231 adolescentes, 24 apresentavam uma grave distorção da imagem corporal, 75,0\% totalizando um número de 18 meninas, e 25\% um total de 6 meninos (Gráfico 7).

Gráfico 7 - Distorção da imagem corporal em adolescentes.

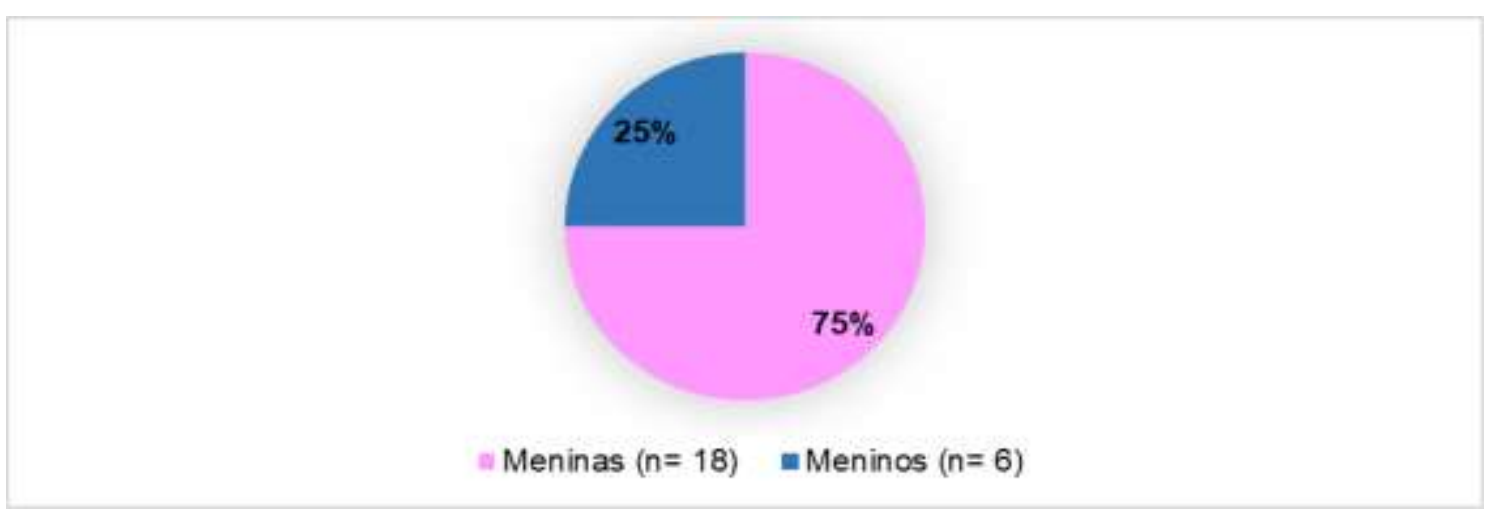

Fonte: Adaptado de Chimbinha, Jácome, Silva, Barreto e Costa (2019).

Além disso, havia uma alta probabilidade de transtornos alimentares presentes nesses 24 adolescentes com idade média desse grupo foi de 16,2 anos. Mediante a entrevista realizada, houve uma confirmação de 9 com transtornos alimentares, e a afirmação para bulimia foram $6,55,5 \%$ (5) meninas e (1) menino $11,1 \%, 33,3 \%$ (3) meninas com anorexia do tipo purgativa (Gráfico 8). 
Gráfico 8 - Transtornos alimentares confirmados em meninos e meninas.

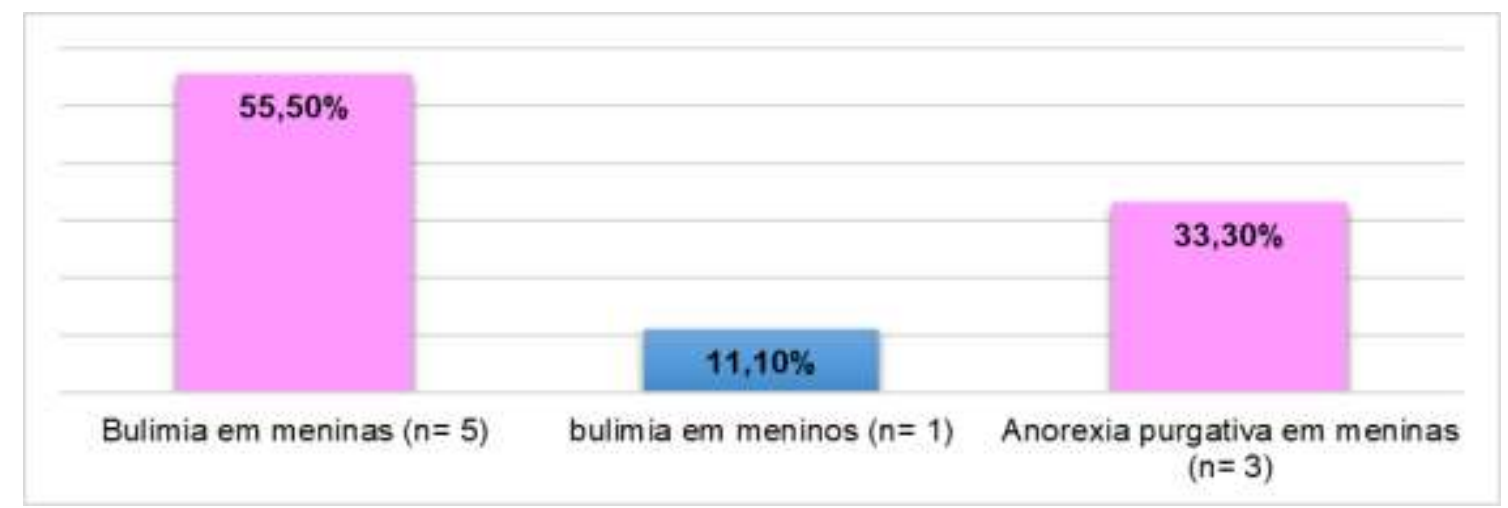

Fonte: Adaptado de Chimbinha, Jácome, Silva, Barreto e Costa (2019)

Saorin e Marco (2018, p. 5-6.) relata que:

"O autoconceito, desenvolvido na segunda infância, quando a criança ainda não sabe distinguir sua imagem real da ideal, pode ser afetado por diversos fatores como um brinquedo com aparência exageradamente magra, uma modelo na televisão, uma fotografia em uma revista, ou até mesmo, as palavras dos pais. Os fatores externalizantes são muitos, afinal, há tantos padrões e influências que é impossível enumerar, mas o que deve ser levado em consideração, é o modo como estes afetam a imagem corporal da criança e acabam influenciando para futuros transtornos alimentares".

O autor ainda cita que com o crescente desenvolvimento da mídia há também um maior investimento das indústrias de brinquedos, mudando o padrão para que se torne mais fixo à mente da sociedade, principalmente ao público infantil, sendo vendidos brinquedos tanto femininos quanto masculinos à partir de modelos ilusórios, modelos esses que não se podem ser alcançados, ocasionando ao indivíduo uma frustação quando a sua aparência física, além da preocupação de como ele é visto por outras pessoas.

\section{Regulamentação de publicidade e propaganda de alimentos}

Para Tatlow-Golden et al. (2021) o controle e monitoramento do marketing de produtos alimentícios voltados para o público infantil é desafiador. Entretanto o monitoramento se faz necessário, podendo contribuir com a redução de Doenças Crônicas não Transmissíveis (DCNT), e obesidade. Hartung e Karageorgiadis (2016) cita que no Brasil, existe a legislação que estabelece que a publicidade dirigida a crianças, qualquer bem e qualquer meio ou mídia é abusiva e, portanto, ilegal, conforme confirmado a decisão do Tribunal Superior, em situações específicas envolvendo alimentos.

No entanto, para Hartung e Karageorgiadis (2016, p. 179),

“O que se vê - não apenas no Brasil, mas no mundo todo - é a visão da criança, por alguns segmentos, como públicoalvo, consumidora atual e futura e promotora de vendas perante suas famílias e seus pares. Assim, o mercado de anunciantes, publicitários e meios de comunicação, de maneira sistemática e fundado em interesses exclusivamente econômicos, descumpre o ordenamento jurídico brasileiro e contesta a validade das normas protetivas da infância com frágeis argumentos que alegam suposta censura, paternalismo estatal indevido ou até mesmo a responsabilidade exclusiva da família sobre o cuidado das crianças".

Um estudo realizado por Correa, Reyes, Taillie, Corvalán e Dillman (2020) analisou anúncios exibidos em canais televisivos no Chile, entre os anos de 2016 e 2017, com intuito de verificar mudanças após ser implantado em 2016 uma regulamentação nacional de marketing nutricional não saudável. Através de seu estudo foi observado que alimentos com elevado teor de gorduras saturadas, sódio e açúcar que eram anunciados em programas direcionados ao público infantil antes 
da restrição, tinha um percentual de $41,9 \%$ e reduziu para 14,8\% após a implantação, diminuindo a exposição de crianças à publicidade de alimentos que não oferecem valor nutricional. Além disso, houve uma redução de 49,7\% para 12,7\% em programas voltados ao público infantil. Enquanto à bebidas processadas, cereais de café da manhã, refrigerantes e guloseimas, tiveram um decréscimo maior. Anúncios voltados a crianças de alimentos ricos em energia, gorduras saturadas, açúcares ou sódio, tiveram uma diminuição considerável de, 44,0\% para 12,0\% (Gráfico 9).

Gráfico 9 - Frequência de anúncios televisivos antes e depois da regulamentação implantada no Chile no ano de 2016.

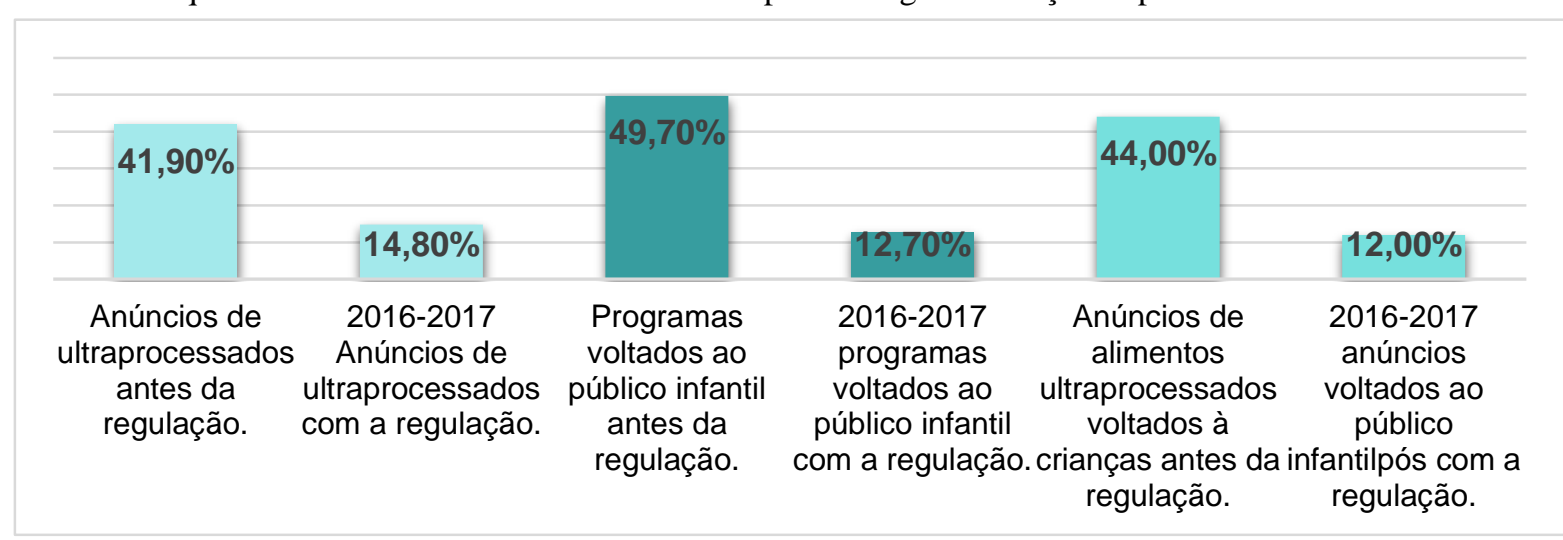

Fonte: Adaptado de Correa, Reyes, Taillie, Corvalán e Dillman (2020)

"Ao contrário da televisão ou da publicidade digital, a embalagem é essencial para a tomada de decisão no ponto de venda". (Elliott \& Truman, 2020). Ainda na visão do autor, as embalagens de alimentos direcionadas ao público infantil são consideradas uma publicidade. Um estudo realizado por Silva et al. (2021) observou que a maior parte de marcas de alimentos possuem páginas de mídia social, essas plataformas são utilizadas para promover seus produtos, além de estabelecer uma comunicação com seus clientes ou futuros clientes. Outra observação importante é que, quase $90 \%$ das marcas dos comerciais transmitidos em canais televisivos brasileiros em 2018 vieram do setor de alimentos ultraprocessados.

De acordo com a Organização Mundial de Saúde (OMS) (2021), algumas pessoas podem sofrer impactos imediatos em suas escolhas alimentares quando visualizam determinados influenciadores ou figuras públicas consumindo determinados alimentos que não são saudáveis.

"No caso da regulamentação da publicidade de alimentos, deve-se considerar a vulnerabilidade do público infantil às estratégias agressivas de marketing” (Henriques, Dias \& Burlandy, 2014). Entretanto, para Hartung e Karageorgiadis (2017) uma proibição efetiva da divulgação de produtos alimentícios dirigida à criança é essencial para proteger seus direitos, integridade física, psicológica e moral.

O mundo digital tem um alcance global, por meio de redes sociais, sites e canais televisivos, sendo uma ferramenta para que indústrias de diversos segmentos divulguem seus produtos, e para ganhar mais visibilidade e lucro, contratam famosos da internet conhecidos como influenciadores digitais, ou atores de novelas e filmes conhecidos pela sociedade. "A OMS/Europa está comprometida em melhorar os métodos de monitoramento e restrição da comercialização digital de produtos não saudáveis para crianças.” (OMS, 2021).

\section{Considerações Finais}

Mediante revisão bibliográfica, o presente trabalho identificou que a mídia tem um grande poder de persuasão nas escolhas alimentares de crianças e adolescentes e, com a utilização do marketing na divulgação de produtos, esse público é atraído ao consumo de alimentos com elevado teor de sódio, gorduras e açucares que ofertam pouco ou nenhum valor nutricional. 
É notável que mesmo diante de legislações que proíbem o marketing alimentar infantil de forma abusiva, ainda assim algumas empresas no ramo alimentício utilizam ferramentas que aumentam suas vendas, ofertando brindes, promoções, personagens e propagandas e que atraem esse público. Em vista disso, são necessárias leis mais rígidas que controlem o que é vendido a esse público.

Em virtude da influência da mídia em relação aos transtornos alimentares em crianças e adolescentes, é possível observar o quanto esse público encontra-se insatisfeito com o corpo, insatisfação essa que os levam a ter atitudes que agravam sua saúde tentando alcançar um padrão de beleza imposto pela mídia.

A educação nutricional em escolas e creches é de extrema importância, já que crianças e adolescentes passam boa parte de seu tempo no ambiente escolar, ensiná-los sobre a importância da alimentação saudável é incentivar boas escolhas alimentares. Além disso, é importante o monitoramento dos pais quanto aos hábitos alimentares de toda a família, priorizando alimentos in natura, ou minimamente processados, e a pratica atividade física.

Por fim, faz-se necessário refletir sobre a importância do monitoramento de publicidades que promovem alimentos que não são saudáveis. Além disso, é imprescindível que todos se conscientizem a respeito das consequências que a obesidade pode causar a longo prazo na saúde de crianças.

\section{Referências}

Alves, M. G. \& Cunha, T. C. O. (2020). A importância da alimentação saudável para o desenvolvimento humano. Revista Perspectivas Online: Humanas \& Sociais Aplicadas. 10(27), 46- 62. https://doi.org/10.25242/8876102720201966

Bankoff, A. D. P., Bispo, I. M. P. \& Sousa, M. A. B. (2020). Estudo da cultura alimentar, hábitos de vida e influências sobre as doenças crônicas não transmissíveis. Revista Saúde e Meio Ambiente, 10(1), 1-18. https://trilhasdahistoria.ufms.br/index.php/sameamb/article/view/9118

Bittar, C. \& Soares, A. (2020). Mídia e comportamento alimentar na adolescência. Cadernos Brasileiros de Terapia Ocupacional. 28(1), 291-308. https://doi.org/10.4322/2526-8910.ctoAR1920

Brasil, V. (2016). Hábitos dos brasileiros impactam no crescimento da obesidade e aumenta prevalência de diabetes e hipertensão. Brasília: Conselho Federal de Nutricionistas. https://portalarquivos2.saude.gov.br/images/pdf/2018/marco/02/vigitel-brasil-2016.pdf

Brandt, L. M. T., Fernandes, L. H. F., Aragão, A. S., Luna, T. C., Feliciano, R. M.; Auad, S. M. \& Cavalcanti, A. L. (2019). "Risk behavior for bulimia among adolescents." Revista Paulista de Pediatria, 37(2), 217-224. http://dx.doi.org/10.1590/1984-0462/;2019;37;2;00008

Casemiro, J. P., Fonseca, A. B. C., Machado, E. C. S. \& Peres, S. C. (2015). Impasses, desafios e as interfaces da educação alimentar e nutricional como processo de participação popular. Trabalho, Educação e Saúde, 13(2), 493-514. https://doi.org/10.1590/1981-7746-sip00051

Cardoso, S., SANTOS, O., NUNES, C. \& LOUREIRO, I. (2015). Escolhas e hábitos alimentares em adolescentes: associação com padrões alimentares do agregado familiar. Revista Portuguesa de Saúde Pública, 33(2), 128-136. https://doi.org/10.1016/j.rpsp.2014.07.004

Chimbinha, Í. G. M., Jácome, A. N., Silva, G. G., Barreto, M. J. R. \& Costa, I. C. C. (2019). Transtornos alimentares e manifestações orais em adolescentes. Revista Ciência Plural, 5(3), 1-20. file:///C:/Users/regim/Downloads/19204-Texto\%20do\%20artigo-61236-1-10-20191112\%20(1).pdf

Coelho, D. E. P. \& Bógus, C. M. (2016). Vivências de plantar e comer: a horta escolar como prática educativa, sob a perspectiva dos educadores. Saúde $e$ Sociedade. 25(3), 761-770. https://doi.org/ 10.1590/S0104-12902016149487

Contreras, J. \& Gracia, M. (2015). Alimentação, Sociedade e Cultura. Fiocruz.

Correa, T., Reyes, M., Taillie, L. S., Corvalán, C. \& Dillman Carpentier, F. R. (2020). Food advertising on television before and after a national unhealthy food marketing regulation in chile, 2016-2017. American Journal of Public Health, 110(7), 1054-1059. https://doi.org/10.2105/AJPH.2020.305658

Dias, J. D., Mekaro, M. S., Cheng Lu, J. K., Otsuka, J. L., Fonseca, L. M. M. \& Zem-Mascarenhas, S. H. (2016). Desenvolvimento de serious game como estratégia para promoção de saúde e enfrentamento da obesidade infantil. Revista Latino-Americana de Enfermagem, 24, 1-9. https://doi.org/ 10.1590/15188345.1015.2759

Dutra, G. \& Malagoli, L. (2019). A construção de um hábito alimentar saudável desde a educação infantil. Revista Gepesvida, 1(9), 116-129. http://www.icepsc.com.br/ojs/index.php/gepesvida/article/view/338

Elliott C. \& Truman E. (2020). The power of packaging: A scoping review and assessment of child-targeted food packaging. Nutrients, 12(4), 1-17, 2020. https://doi.org/10.3390/nu12040958

Engler, R. C., Guimarães, L. H. \& Lacerda, A. C. G. (2016). Design e consumo: a influência da mídia sobre a obesidade infantil. Blucher Design Proceedings, 9(2, 5626-5637. http://pdf.blucher.com.br.s3-sa-east-1.amazonaws.com/designproceedings/ped2016/0529.pdf 
Enes, C. C. \& Lucchini, B. G. (2016). Tempo excessivo diante da televisão e sua influência sobre o consumo alimentar de adolescentes. Revista de Nutrição.29(3), 391-399. https://doi.org/10.1590/1678-98652016000300009

Ferreira, A. P. D. S., Szwarcwald, C. L. \& Damacena, G. N. (2019). Prevalência e fatores associados da obesidade na população brasileira: estudo com dados aferidos da Pesquisa Nacional de Saúde, 2013. Revista Brasileira de Epidemiologia, 22, 1-14. https://doi.org/10.1590/1980-549720190024

Frank, G. K., Deguzman, M. C. \& Shott, M. E. (2019). "Motivação para comer e não comer - O conflito psicobiológico na anorexia nervosa." Physiology \& behavior, 206, 185-190. https://doi.org/10.1016/j.physbeh.2019.04.007

Freitas, N. B. \& Souza C. C. K. (2020). Prática de dietas e risco para transtornos alimentares: Revisando as evidências científicas. RBONE-Revista Brasileira de Obesidade, Nutrição e Emagrecimento, 14(88), 735-744, 2020. http://www.rbone.com.br/index.php/rbone/article/view/1371

Fortes, L. D. S., Filgueiras, J. F., Oliveira, F. D. C., Almeida, S. S. \& Ferreira, M. E. C. (2016). Modelo etiológico dos comportamentos de risco para os transtornos alimentares em adolescentes brasileiros do sexo feminino. Cadernos de Saúde Pública, 32(4), 4-11. http://dx.doi.org/10.1590/0102-311X00024115

Furtado, M. A. \& Szapiro, A. M. (2016). Política Nacional de Promoção da Saúde: os dilemas da autonomização. Saúde e Sociedade, 25 (2), $277-289$. https://doi.org/ 10.1590/S0104-12902016149175

Giugliani, E. R. J. (2018). Crescimento dentro exclusivamente amamentado bebês. Jornal de Pediatria, 95(1), 79-84. https://doi.org/10.1016/j.jpedp.2018.11.022

Gravatá, R. C. F., Alves, S. C. S. \& Fernandes, S. C. S. (2019). A influência da mídia no consumismo infantil: uma revisão de literatura. Revista Brasileira de Iniciação Científica, 6(7), 41-56. Disponível em:<file:///C:/Users/regim/Downloads/1326-6117-1-PB.pdf

Greenwood, S. A. \& Fonseca, A. B. (2016). Espaços e caminhos da educação alimentar e nutricional no livro didático. Ciência \& Educação (Bauru), 22(1), 201-218. https://doi.org/10.1590/1516-731320160010013

Hartung, P. A. D. \& Karageorgiadis, E. V. (2017). A regulação da publicidade de alimentos e bebidas não alcoólicas para crianças no Brasil. Revista de Direito Sanitário, 17(3), 160-184. http://dx.doi.org/10.11606/issn.2316-9044.v17i3p160-184

Henriques, P., Sally, E. O., Burlandy, L. \& Beiler, R. M. (2012). Regulamentação da propaganda de alimentos infantis como estratégia para a promoção da saúde. Ciência \& Saúde Coletiva, 17(2),481-490. https://www.scielosp.org/pdf/csc/2012.v17n2/481-490/pt

Henriques, P.,Dias, P.C. \& Burlandy, L. (2014). A regulamentação da propaganda de alimentos no Brasil: convergências e conflitos de interesses. Cadernos de Saúde Pública, 30(6), 1219-1228. https://doi.org/10.1590/0102-311X00183912

Lira, A. G., Ganen, A. D. P., Lodi, A. S. \& Alvarenga, M. D. S. (2017). Uso de redes sociais, influência da mídia e insatisfação com a imagem corporal de adolescentes brasileiras. Jornal Brasileiro de Psiquiatria, 66(3), 164-171. https://doi.org/10.1590/0047-2085000000166

Machado, N. O., Ferreira, R. H. \& Rangel, T. L. V. (2019). Obesidade infantil decorrente da má-alimentação: uma análise à luz da revisão de literatura. Revista Científica Interdisciplinar, 4(1), 25-40. http://www.multiplosacessos.com/multaccess/index.php/multaccess/article/view/100

Martins, A. P. B. (2018). É preciso tratar a obesidade como um problema de saúde pública. Revista de Administração de Empresas. 58(3), 337-341. https://doi.org/10.1590/S0034-759020180312

Marini, M. (2016). "Você poderá vomitar até o infinito, mas não conseguirá retirar sua mãe de seu interior" 1-psicanálise, sujeito e transtornos alimentares." cadernos pagu, (46), 373-409. https://doi.org/10.1590/180944499201600460373

Moura, N.C. (2010). Influência da mídia no comportamento alimentar de crianças e adolescentes. Segurança Alimentar e Nutricional, 17(1), 113-122. https://doi.org/10.20396/san.v17i1.8634805

Neale, J. \& Hudson, L. (2020). Anorexia nervosa em adolescentes. British Journal of Hospital Medicine, 81(6), 1-8. https://doi.org/10.12968/hmed.2020.0099

Oliveira, M. R. \& Machado, J. S. A. (2021). O insustentável peso da autoimagem:(re) apresentações na sociedade do espetáculo. Ciência \& Saúde Coletiva, 26(7), 2663-2672. https://doi.org/10.1590/1413-81232021267.08782021

Organização Mundial de Saúde (OMS). (2018). Ilustrando sucessos e desafios no enfrentamento da obesidade infantil na Assembleia Geral das Nações Unidas. https://www.euro.who.int/en/health-topics/Life-stages/child-and-adolescent-health/news/news/2018/10/illustrating-successes-and-challenges-intackling-childhood-obesity-at-the-united-nations-general-assembly

Organização Mundial de Saúde (OMS). (2021). Nossas escolhas são individuais, mas podem ser influenciadas - celebridades de alto perfil têm o poder de incentivar comportamentos saudáveis. https://www.euro.who.int/en/health-topics/Life-stages/child-and-adolescent-health/news/news/2021/6/our-choices-areindividual-but-can-be-influenced-high-profile-celebrities-have-the-power-to-encourage-healthy-behaviours.

Paiva, J. B. D., Magalhães, L. M., Santos, S. M. C. D., Santos, L. A. D. S. \& Trad, L. A. B. (2019). A confluência entre o "adequado" e o "saudável”: análise da instituição da noção de alimentação adequada e saudável nas políticas públicas do Brasil. Cadernos de Saúde Pública, 35(8), 112. https://doi.org/10.1590/0102-311X00250318

Pedraza, D. F., Silva, F. A., Melo, N. L. S. D., Araujo, E. M. N. \& Sousa, C. P. D. C. (2017). Estado nutricional e hábitos alimentares de escolares de Campina Grande, Paraíba, Brasil. Ciência \& saúde Coletiva, 22(2), 469-477. https://doi.org/10.1590/1413-81232017222.26252015

Penha, J. T., Gazolla, F. M., Miranda Carvalho, C. N., Madeira, I. R., Rodrigues-Júnior, F., Amorim Machado, E. \& Collett-Solberg, P. F. (2019). Physical fitness and activity, metabolic profile, adipokines and endothelial function in children. Jornal de Pediatria, 95(5), 531-537. file://C:/Users/regim/Downloads/1-s2.0-S2255553618301150-main.pdf

Pereira A. S. et al. (2018). Metodologia da pesquisa científica. UFSM. 
Pereira, T. S., Pereira, R. C. \& Angelis-Pereira, M. C. (2017). Influência de intervenções educativas no conhecimento sobre alimentação e nutrição de adolescentes de uma escola pública. Ciência \& Saúde Coletiva, 22(2), 427-435. https://doi.org/10.1590/1413-81232017222.16582015

Penteado, R. Z., Costa, B. C. G. D. \& RODRIGUES, P. H. G. N. (2018). Imaginários no cinema de animação: estetização de corpos na interface do cuidado de crianças e adolescentes. Saúde e Sociedade, 27(2), p. 381-397. https://doi.org/10.1590/S0104-12902018170777

Prado, C. C., Sousa Junior, C. E.\& Pires, M. L. (2017). Histórias em quadrinhos: uma ferramenta para a educação e promoção da saúde. Revista Eletrônica de Comunicação, Informação e Inovação em Saúde, 11(2). https://doi.org/10.29397/reciis.v11i2.1238

Rocha, N. P., Milagres, L. C., Filgueiras, M. D. S., Suhett, L. G., Silva, M. A., Albuquerque, F. M. D., Ribeiro, A. Q., Vieira, S. A. \& Novaes, J. F. D. (2019). Associação dos Padrões Alimentares com Excesso de Peso e Adiposidade Corporal em Crianças Brasileiras: Estudo Pase-Brasil. Arquivos Brasileiros de Cardiologia, 113(1), 52-59. https://doi.org/ 10.5935/abc.20190113

Ross, D. A., Hinton, R., Brewer, M.M., Engel, D., Zeck, W., Fagam, L., Herat, J., Phaladi, G., Jácome, D. I., Anyona, P., Sanchez, A., Damji, N., Terki, F., Baltag, V., Patton, G., Silverman, A., Fogstad, H., Benerjee, A. \& Mohan, A. Adolescent well-being: A definition and conceptual framework. Journal of Adolescent Health, 67(4), 472-476, 2020. https://doi.org/10.1016/j.jadohealth.2020.06.042

Royo-Bordonada, M. Á., Bosqued-Estefanía, M. J., Damián, J., López-Jurado, L. \& Moya-Geromini, M. Á. (2016). Nutrition and health claims in products directed at children via television in Spain in 2012. Gaceta sanitária, 30(3), 221-226. https://doi.org/10.1016/j.gaceta.2016.01.004

Santos, A. P. M. \& Bergold, L. B. (2018). Oficinas musicais: a utilização do lúdico e da música para Educação Alimentar e Nutricional com escolares. Revista da Associação Brasileira de Nutrição-RASBRAN, 9(2), 88-93. https://www.rasbran.com.br/rasbran/article/view/855

Santos, B., Silva, C. \& Pinto, E. (2018). Importância da escola na educação alimentar em crianças do primeiro ciclo do ensino básico - como ser mais eficaz. Associação Portuguesa de Nutrição. 14(2018),18-23. http://dx.doi.org/10.21011/apn.2018.1404

Santos, M. A. D., Oliveira, V. H. D., Peres, R. S., Leonidas, C. \& Oliveira-Cardoso, É. A. D. (2019). Corpo, saúde e sociedade de consumo: a construção social do corpo saudável. Saúde e Sociedade. 28(3), 239-252. https://doi.org/10.1590/S0104-12902019170035

Santos, S. L. \& Batalha, M. O. (2010). Propaganda de alimentos na televisão: uma ameaça à saúde do consumidor? Revista de Administração, 45(4), 373-382. https://doi.org/10.1016/S0080-2107(16)30468-X

Saorin, J.S.\& Marco, T. T. (2018). A influência dos brinquedos nos transtornos alimentares. Anuário Pesquisa e Extensão Unoesc Videira, 3, 1-12, 2018. https://portalperiodicos.unoesc.edu.br/apeuv/article/view/19906/10571

Silva, G. A., Costa, K. A. \& Giugliani, E. R. (2016). Alimentação infantil: além dos aspectos nutricionais. Jornal de Pediatria, $92(3)$, p. $2-7$. https://doi.org/10.1016/j.jped.2016.02.006

Silva, J. G. \& Ferreira, M. A. (2019). Alimentação e saúde na perspectiva de adolescentes: contribuições para a promoção da saúde. Texto \& ContextoEnfermagem, 28. https://doi.org/10.1590/1980-265X-TCE-2018-0072

Silva, J. M., Rodrigues, M, N., Matos, J. P., Mais, L. A., Martins, A. P. B., Claro, R. F. \& Horta, P. M. (2021). "Use of persuasive strategies in food advertising on television and on social media in Brazil." Preventive Medicine Reports, 24, 1-7. https://doi.org/10.1016/j.pmedr.2021.101520

Sousa, B. C. D., Medeiros, D. S. D., Curvelo, M. H. D. S., Silva, E. K. P. D., Teixeira, C. S. S., Bezerra, V. M., Souzas, R. \& Leite, A. J. M. (2019). Hábitos alimentares de adolescentes quilombolas e não quilombolas da zona rural do semiárido baiano, Brasil. Ciência \& Saúde Coletiva, 24(2), 419-430. https://doi.org/10.1590/1413-81232018242.34572016.

Schebendach, J. E. \& Roth, J. (2018). Nutrição nos Transtornos alimentares. In: Mahan, L. K. \& Raymond, J. L. Krause alimentos, nutrição e dietoterapia. 14 ed. Rio de Janeiro: Elsevier, 407-425.

Tatlow-Golden, M., Jewell, J., Zhiteneva, O., Wickramasinghe, K., Breda, J. \& Boyland, E. (2021). Rising to the challenge: Introducing protocols to monitor food marketing to children from the World Health Organization Regional Office for Europe. Obesity Reviews, 1-15. https://doi.org/10.1111/obr.13212

Warkentin, S., Mais, L. A., Latorre, M. R., Carnell, S. \& Taddei, J. A. A. (2018). Factors associated with parental underestimation of child's weight status. Jornal de Pediatria, 94(2), 162-169. https://doi.org/10.1016/j.jpedp.2017.09.001

Willig, M. H., Lenardt, M. H. \& Caldas, C. P. (2015). A longevidade segundo histórias de vida de idosos longevos. Revista Brasileira de Enfermagem. 68(4), 697-704, https://doi.org/10.1590/0034-7167.2015680418i

Zanolli, N. M. B. C., Cândido, A. P. C., Oliveira, R. M. S., Mendes, L. L., Netto, M. P. \& Souza, A. I. S. (2019). "Fatores associados com a insatisfação corporal de crianças e adolescentes de escola pública em município da Zona da Mata mineira". Revista de APS, 22(1). https://doi.org/10.34019/18098363.2019.v22.16400

Zickgraf, H. F. \& Elkins, A. (2018). Sensory sensitivity mediates the relationship between anxiety and picky eating in children/adolescents ages 8-17, and in college undergraduates: A replication and age-upward extension. Appetite, 128, 333-339. https://doi.org/10.1016/j.appet.2018.06.023 